\title{
Assessment of cardiovascular risk of patients with arterial hypertension of a public health unit
}

\author{
Avaliação do risco cardiovascular de indivíduos portadores de \\ hipertensão arterial de uma unidade pública de saúde
}

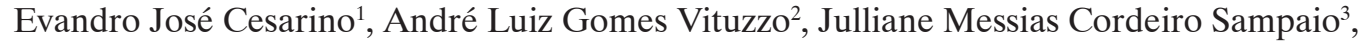 \\ Danilo Avelar Sampaio Ferreira ${ }^{4}$, Heloísa Andrião Ferreira Pires ${ }^{5}$, Luiz de Souza ${ }^{6}$
}

\begin{abstract}
Objective: To assess the cardiovascular risk, using the Framingham risk score, in a sample of hypertensive individuals coming from a public primary care unit. Methods: The caseload comprised hypertensive individuals according to criteria established by the JNC VII, 2003, of 2003, among 1601 patients followed up in 1999, at the Cardiology and Arterial Hypertension Outpatients Clinic of the Teaching Primary Care Unit, at the Faculdade de Medicina de Ribeirão Preto, Universidade de São Paulo. The patients were selected by draw, aged over 20 years, both genders, excluding pregnant women. It was a descriptive, crosssectional, observational study. The Framingham risk score was used to stratify cardiovascular risk of developing coronary artery disease (death or non-fatal acute myocardial infarction). Results: Age range of 27-79 years $(\bar{x}=63.2 \pm 9.58)$. Out of 382 individuals studied, $270(70.7 \%)$ were female and $139(36.4 \%)$ were characterized as high cardiovascular risk for presenting diabetes mellitus, atherosclerosis documented by event or procedure. Out of 243 stratified patients, 127 (52.3\%) had HDL-C < $50 \mathrm{mg} / \mathrm{dL} ; 210$ (86.4\%) had systolic blood pressure $\geq 120 \mathrm{mmHg}$; 46 (18.9\%) were smokers; 33 (13.6\%) had a high cardiovascular risk. Those added to 139 enrolled directly as high cardiovascular risk, totaled up $172(45 \%) ; 77(20.2 \%)$ of medium cardiovascular risk and $133(34.8 \%)$ of low risk. The highest percentage of high cardiovascular risk individuals was aged over 70 years; those of medium risk were aged over 60 years; and the low risk patients were aged 50 to 69 years. Conclusion: The significant number of high and medium cardiovascular risk individuals indicates the need to closely follow them up.
\end{abstract}

Keywords: Hypertension/prevention \& control; Cardiovascular diseases/ prevention \& control; Dyslipidemias; Hypercholesterolemia; Smoking; Primary prevention; Risk assessment; Health centers

\section{RESUMO}

Objetivo: Identificar o risco cardiovascular, por meio do escore de risco de Framinghan, em uma amostra de hipertensos de uma unidade pública de saúde. Métodos: A casuística foi constituída por hipertensos, segundo critérios do JNC VII, 2003, de 2003, dentre 1.601 acompanhados no ano de 1999 no Ambulatório de Cardiologia e Hipertensão Arterial do Centro Saúde Escola da Faculdade de Medicina de Ribeirão Preto da Universidade de São Paulo. Os pacientes foram selecionados por sorteio, com idade acima de 20 anos, ambos os gêneros, excluindo-se as gestantes. Tratou-se de estudo observacional descritivo e transversal. Utilizou-se o Escore de Risco de Framinghan para estratificação do risco cardiovascular para desenvolvimento de doença arterial coronária (morte ou infarto agudo do miocárdio - não fatal). Resultados: A idade variou de 27 a 79 anos $(\bar{x}=63,2 \pm 9,58)$. Dos 382 indivíduos estudados, $270(70,7 \%)$ eram mulheres e $139(36,4 \%)$ foram caracterizados como de alto risco cardiovascular por apresentarem diabetes mellitus, aterosclerose documentada por evento ou procedimento. Dos 243 estratificados, 127 $(52,3 \%)$ apresentaram HDL-C $<50 \mathrm{mg} / \mathrm{dL} ; 210(86,4 \%)$ apresentaram pressão arterial sistólica $\geq 120 \mathrm{mmHg} ; 46(18,9 \%)$ eram fumantes; $33(13,6 \%)$ eram de alto risco cardiovascular - que somados aos 139 incluídos diretamente como alto risco cardiovascular, totalizaram $172(45 \%) ; 77(20,2 \%)$ eram de médio risco cardiovascular e 133 $(34,8 \%)$ de baixo risco. 0 maior percentual de indivíduos de alto risco cardiovascular situou-se acima 70 anos; de médio risco, acima de 60 anos; e de baixo risco entre 50 e 69 anos. Conclusão: 0 número significativo de indivíduos de alto e médio risco cardiovascular indica a necessidade de um acompanhamento mais próximo dos mesmos.

Descritores: Hipertensão/prevenção \& controle; Doenças cardiovasculares/ prevenção \& controle; Dislipidemias, hipercolesterolemia; Tabagismo, prevenção primária; Medição de risco; Centros de saúde

\footnotetext{
Study carried out at Centro Saúde Escola, Faculdade de Medicina de Ribeirão Preto, Universidade de São Paulo - USP, Ribeirão Preto (SP), Brazil.

' Faculdade de Ciências Farmacêuticas de Ribeirão Preto, Universidade de São Paulo - USP, Ribeirão Preto (SP), Brazil.

2 Undergraduate, Faculdade de Ciências Farmacêuticas de Ribeirão Preto, Universidade de São Paulo - USP, Ribeirão Preto (SP), Brazil.

${ }^{3}$ Associação Ribeirão-pretana de Ensino, Pesquisa e Assistência ao Hipertenso - Ribeirão Preto (SP), Brazil.

${ }^{4}$ Graduate Program (PhD), Faculdade de Ciências Farmacêuticas de Ribeirão Preto, Universidade de São Paulo - USP, Ribeirão Preto (SP), Brazil.

${ }^{5}$ Undergraduate, Faculdade de Filosofia, Ciências e Letras de Ribeirão Preto, Universidade de São Paulo - USP, Ribeirão Preto (SP), Brazil.

${ }^{6}$ Pediatrics and Infant Care, Faculdade de Medicina de Ribeirão Preto, Universidade de São Paulo - USP, Ribeirão Preto (SP), Brazil.

Corresponding author: Evandro José Cesarino - Campus Universitário da USP - Faculdade de Ciências Farmacêuticas de Ribeirão Preto - Avenida do Café, s/n - Monte Alegre - Zip code: $14040-903$ Ribeirão Preto (SP), Brazil - Phone: (16) 3602-4708 - E-mail: cesarino@fcfrp.usp.br

Received: Jul 31, 2010 - Accepted on: Dec 15, 2011

Conflict of interest: None
} 


\section{INTRODUCTION}

Cardiovascular diseases (CVD), according to the World Health Organization (WHO) account for 16.7 million deaths per year. The estimates for 2020 maintain these conditions as the main cause of death, with developing countries contributing more significantly than developed countries $^{(1)}$

In Brazil, CVD are the main cause of death in those aged over 40 years. A total of 283927 deaths due to diseases of the circulatory system (CSD) were recorded in 2005 , i.e., $32.2 \%$ of all deaths in that year ${ }^{(2,3)}$.

A study carried out in Brazil, analyzing mortality due to CVD in the five geographic regions revealed a trend to decrease in mortality in the population older than 30 years of age in the North, Southeast and South regions. However, in the Northeast and Center-Western regions, a trend to an increased risk of death due to CVD was observed. This different findings observed in the different geographic regions show the importance and variability of regional analysis of CVD and the risk of death in the less-favored regions from the socioeconomic viewpoint ${ }^{(4)}$.

A study sponsored by the Pan American Health Organization (PAHO), published in 1967, about the annual mortality rates adjusted by sex, age and hypertensive heart diseases per 100000 individuals, from 1962 to 1964, showed the cities of Ribeirão Preto (SP) (34.2), Sao Paulo (SP) (31.7) and Cali (Colombia) (31.6) as those with the highest mortality rates due to hypertensive heart disease ${ }^{(5)}$.

In 1995, circulatory system diseases accounted for $30.8 \%$ of deaths among individuals living in Ribeirão Preto (SP). There were 199 deaths due to acute myocardial infarction (AMI) $(6.5 \%)$, with this being the second main basic cause of deaths among people living in that city ${ }^{(6)}$.

Cardiovascular risk factor (CRF) is understood as features or pathological situations that are positively correlated with ischemic heart disease (IHD). This concept emerged from prospective epidemiological studies evaluating population samples for long periods of time showing this association. The term "risk factor" appeared for the first time in the medical literature only in $1963^{\prime}(7-9)$.

The Framingham study, carried out in Massachusetts, USA, started in 1948, with its observation and field work, after 1950, with the follow-up of about 5000 adults aged 39-59 years without CVD. In 1957, a preliminary analysis showed that men with systemic arterial hypertension (SAH), obesity or hypercholesterolemia at baseline presented a rate of coronary events that was two to six times higher than those not exposed to these conditions. A further report, of a 6-year followup, added smoking habit as another predictor for the risk of $\operatorname{IHD}^{(7-9)}$.

The search of modes of preventing CVD aim to reduce morbidity/mortality and, therefore, improve the life quality and expectancy. The study of responsible factors, their identification and stratification allow the development of preventive programs ${ }^{(10)}$.

Stratification of cardiovascular risk in patients with SAH is composed of: (1) major risk factors: smoking habit, dyslipidemia, diabetes mellitus (DM), age over 60 years, gender (men or postmenopausal women), family history of CVD (woman aged under 65 years or man under 55 years) and (2) injury to target organs and clinical manifestations of CVD, such as heart diseases (left ventricular hypertrophy LVH, angina or previous AMI, previous myocardial revascularization surgery (MRS) and congestive heart failure (CHF); stroke (cerebrovascular accident) or transient ischemic attack, nephropathy, peripheral artery disease and retinopathy ${ }^{(11)}$.

\section{OBJECTIVE}

To assess the cardiovascular risk in a sample of hypertensive individuals coming from a public primary care unit including comparative analysis between the genders.

\section{METHODS}

\section{Patients}

A descriptive, cross-section, observational study, whose caseload was made up of a sample of 382 individuals with $\mathrm{SAH}$ (of these, 139 were directly included as patients with a high cardiovascular risk and 243 underwent evaluation by the Framingham cardiovascular risk score - FRS), according to criteria of the Joint National Committee on Prevention, Detection, Evaluation, and Treatment of High Blood Pressure (JNC VII), of 2003 $3^{(12)}$, among 1601 patients seen in 1999, at the Professor Sérgio Henrique Ferreira Cardiology and Arterial Hypertension outpatient clinic of the School Health Unit, at the Faculdade de Medicina de Ribeirão Preto, Universidade de São Paulo (USP). These individuals were randomly numbered and selected, by a drawing, to avoid sampling bias.

The individuals included in the study were only adults older than 20 years of age, of both genders; pregnant women and elderly individuals aged 80 years or older were excluded for not being able to be stratified by the FRS (Framigham risk score). 
The study was submitted to and approved by the Research Ethics Committee, at the Faculdade de Ciências Farmacêuticas de Ribeirão Preto da USP.

\section{Protocol}

After randomization, the patient was asked to sign an informed consent declaration, read along with the patient, with clarification of all the patients' doubts about this study and a copy with the same content was handed to the patient. After this procedure, the individuals were enrolled in the study.

A standard instrument was used for the investigation, composed of an ERF card filled out by the investigator after the end of laboratory exams (cholesterol, HDL, LDL, triglycerides and blood glucose) and further count of the points for stratification of cardiovascular risk in 10 years for the development of IHD (death or non-fatal AMI).

The study subjects could be using any antihypertensive drug.

The Framingham study is the theoretical reference of cardiovascular risk factors (CVRF) mostly used worldwide, which evidences a causal relationship with CVD. As revealed by data of the present study, cardiovascular risk factors such as SAH, DM, smoking habit and dyslipidemia are independent CVRF for the development of CVD. Thus, based on the importance of these, an adequate stratification of the cardiovascular risk is justified for the future occurrence of CVD by using the FRS. The score is calculated by adding the points assigned to the CVRF separately for males and females. This calculation can classify the individual as a high, medium or low risk of developing CVD in the next 10 years $^{(13,14)}$.

FRS calculates the absolute risk of coronary events (death, AMI and angina pectoris - AP) in 10 years. Scores are assigned to age, systolic blood pressure (SBP), total cholesterol, HDL cholesterol and smoking habit (any cigarette in the last month). In case of a discrepancy between SBP and diastolic blood pressure (DBP), the highest level must be used for score purposes.

The absolute risk of IHD is the real risk of AMI, death related to IHD or AP in a certain period of time.

The risk of IHD is proportional to the number and intensity of CVRF and it can be characterized by the FRS as:

- high: absolute risk > 20\% in 10 years;

- medium: absolute risk of 10 to $20 \%$ in 10 years;

- low: absolute risk $<10 \%$ in 10 years.

\section{Statistical analysis}

Statistical analysis comprised the calculation of descriptive statistics, such as means, medians, minimum values, maximum values and standard deviation for the pertinent variables, as well as the use of Fisher's exact test for comparison between groups.

Database was formed by means of Epi-Info program, version 6.04, for detailed analysis of FRS form.

\section{RESULTS}

The age of individuals enrolled in the study ranged from 27 to 79 years, with a mean of 63.2 years and standard deviation of 9.6 years. Of the 382 individuals studied, $270(70.7 \%)$ were females (Table 1$)$.

\section{Triglycerides}

Of the 382 individuals studied, 139 (36.4\%) presented triglycerides levels $\geq 150 \mathrm{mg} / \mathrm{dL}$ and, of those, $96(69.1 \%)$ were females. In the female group, it was observed that $96(35.6 \%)$ individuals had triglyceride levels above normal levels and, among males, 43 (38.4\%) individuals had triglyceride levels above normal levels.

\section{Direct characterization as patients with high cardiovascular risk}

Of the individuals studied, 139 (36.4\%) were characterized as having a high cardiovascular risk for presenting DM, atherosclerosis detected by an event (stroke or AMI) or atherosclerosis detected by a procedure (myocardial revascularization, surgery with placement of saphenous bypass or thoracic (mammary) artery and transluminal coronary angioplasty - TCA, by means of a balloon or an intracoronary stent) (Table 2).

The FRS for these individuals was not calculated since they are directly stratified as high cardiovascular risk.

The same individual may have presented more than one factor or associated condition.

Table 1. Distribution of hypertensive individuals from a public primary care unit in Ribeirão Preto (SP), according to gender and age group

\begin{tabular}{lccc}
\hline Age group & $\begin{array}{c}\text { Male } \\
\mathbf{n}\end{array}$ & $\begin{array}{c}\text { Female } \\
\mathbf{n}\end{array}$ & $\begin{array}{c}\text { Total } \\
\mathbf{n}\end{array}$ \\
\hline $20-59$ & 40 & 80 & 120 \\
$60-69$ & 35 & 109 & 144 \\
$70-79$ & 37 & 81 & 118 \\
\hline Total & $112(29,3 \%)$ & $270(70,7 \%)$ & $382(100 \%)$ \\
\hline Fischer's exact test: $p=0.228$. & & &
\end{tabular}


Table 2. Frequency of factors that lead hypertensive individuals of a public primary care unit in Ribeirão Preto (SP) directly to the group of high cardiovascular risk

\begin{tabular}{lc}
\hline Cardiovascular risk factor or associated condition & Frequency \\
\hline Diabetes mellitus & 92 \\
Atherosclerosis documented by an event & 79 \\
Atherosclerosis documented by a procedure & 20 \\
\hline
\end{tabular}

\section{HDL-C}

Of the 243 individuals stratified by the FRS, 127 $(52.3 \%)$ presented HDL-C $<50 \mathrm{mg} / \mathrm{dL}, 63(25.9 \%)$ between 50 and $59 \mathrm{mg} / \mathrm{dL}$, and $53(21.8 \%)>60 \mathrm{mg} / \mathrm{dL}$.

\section{Total cholesterol}

Of the 243 individuals stratified by the FRS, $212(87.2 \%)$ presented total cholesterol $\geq 200 \mathrm{mg} / \mathrm{dL}$.

\section{SBP}

Of the 243 individuals stratified by the FRS, 33 (13.6\%) presented blood pressure levels $<120 \mathrm{~mm} \mathrm{Hg}$ and 210 $(86.4 \%)$ individuals had levels that were equal or higher than this value.

\section{Smoking habit}

Of the 243 individuals stratified by the FRS, 46 (18.9\%) were smokers and $197(81.1 \%)$ did not report a history of smoking habit. It was observed that approximately four in ten men were smokers and only one in ten women had this habit.

\section{Stratification of cardiovascular risk by FRS}

Among the patients, 33 (13.6\%) were characterized as patients with high cardiovascular risk. Along with the other individuals (139) enrolled directly as high cardiovascular risk, they made up a total of $45 \%$ of individuals in the studied sample.

As to the total, 77 (31.7\%) individuals were characterized as patients with medium cardiovascular risk. These individuals represent $20.1 \%$ of the sample studied.

Compared to the total number of individuals, $133(54.7 \%)$ individuals were characterized as low cardiovascular risk. These individuals represent $34.8 \%$ of the studied sample (Figure 1).

\section{Stratification of cardiovascular risk versus age}

The most significant percentage of high cardiovascular risk was observed in the age group $>70$ years. In

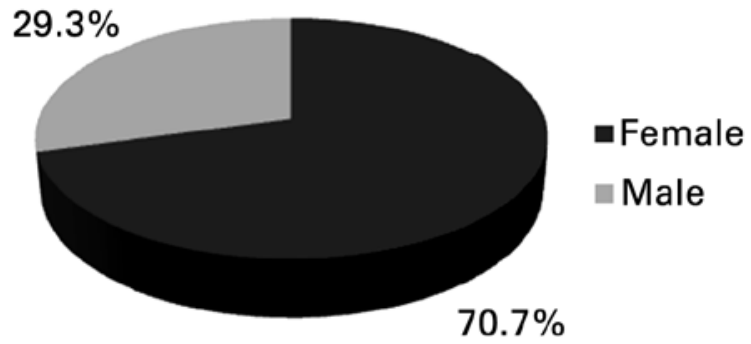

Figure 1. Distribution of hypertensive individuals of a public primary care unit in Ribeirão Preto (SP), according to gender

regard to medium risk, there was a predominance of individuals in the age group $>60$ years and low risk in the age group between 50 and 69 years.

Fisher's exact test detected significant differences in risk in the several age groups $(p<0.001)$. High and medium cardiovascular risks were more frequent in patients $>70$ years old, and low cardiovascular risk was more frequent in patients $<70$ years (Table 3 ).

\section{Stratification of cardiovascular risk versus gender}

A predominance of female gender was observed in the 139 individuals characterized directly as high cardiovascular risk: 88 (63.3\%). It was also noted that, in regard to the total number of individuals in the studied sample, a higher percentage of male gender was characterized directly as high cardiovascular risk due to presenting DM or atherosclerosis (45.5\%), compared to the female individuals (32.6\%), a fact confirmed after the use of the Fisher's test.

In regard to individuals stratified by FRS, there was a higher percentage of male individuals characterized as medium and high cardiovascular risk (45.9 and $32.8 \%$ ), while in females, the higher percentage was characterized as low cardiovascular risk $(65.9 \%)$. The risk difference between male and female individuals was significant, according to the Fisher's test $(p<0.001)$ (Table 4). Age distribution according to gender was considered homogeneous $(\mathrm{p}=0.228)$ (Table 1$)$.

Table 3. Distribution of hypertensive individuals in a public primary care unit in Ribeirão Preto (SP) stratified by the Framingham score risk, according to age group and cardiovascular risk

\begin{tabular}{lcccc}
\hline \multirow{2}{*}{$\begin{array}{l}\text { Age group } \\
\text { (years) }\end{array}$} & $\begin{array}{c}\text { High } \\
\mathbf{n}\end{array}$ & $\begin{array}{c}\text { Medium } \\
\mathbf{n}\end{array}$ & $\begin{array}{c}\text { Low } \\
\mathbf{n}\end{array}$ & $\begin{array}{c}\text { Total } \\
\mathbf{n}\end{array}$ \\
\cline { 2 - 5 } & 4 & 15 & 71 & 90 \\
$50-59$ & 8 & 28 & 54 & 90 \\
$60-69$ & 21 & 34 & 8 & 63 \\
$70-79$ & 33 & 77 & 133 & 243 \\
\hline Total & & &
\end{tabular}

Fischer's exact test: $p<0.001$ 


\section{Stratification of cardiovascular risk versus LDL-C}

After stratification of cardiovascular risk, limits for LDL-C were defined as: individuals with high cardiovascular risk: LDL-C $<100 \mathrm{mg} / \mathrm{dL}$; individuals with medium cardiovascular risk: LDL-C $<130 \mathrm{mg} / \mathrm{dL}$, and individuals with low cardiovascular risk: LDL-C $<160 \mathrm{mg} / \mathrm{dL}$. Five individuals (four women) did not have their LDL-C calculated because they presented triglyceride levels > $400 \mathrm{mg} / \mathrm{dL}$, and Friedwald's equation could not be used ${ }^{(15)}$. These individuals were directly characterized with high cardiovascular risk due to presenting DM or atherosclerosis.

We observed a significant percentage of individuals with LDL-cholesterol $\geq 100 \mathrm{mg} / \mathrm{dL}$ (69.8\%). Female individuals presented a higher percentage in their group with increased LDL-C level (75\%) compared with male individuals $(60.7 \%)$.

Of 243 individuals who had their FRS calculated, $36.6 \%$ presented uncontrolled levels of LDL-C according to the already described targets, while in individuals with uncontrolled LDL-C, the highest frequency was in the group with high cardiovascular risk $(46.1 \%)$ and, in individuals with controlled LDL-C, the highest frequency was in the group with low cardiovascular risk $(71.4 \%)$.

Table 4. Distribution of hypertensive individuals in a public health unit in Ribeirão Preto (SP) stratified by the Framingham risk score, according to gender and cardiovascular risk

\begin{tabular}{lcccc}
\hline \multirow{2}{*}{ Gender } & \multicolumn{4}{c}{ Cardiovascular risk } \\
\cline { 2 - 5 } & $\begin{array}{c}\text { High } \\
\mathbf{n}\end{array}$ & $\begin{array}{c}\text { Medium } \\
\mathbf{n}\end{array}$ & $\begin{array}{c}\text { Low } \\
\mathbf{n}\end{array}$ & $\begin{array}{c}\text { Total } \\
\mathbf{n}\end{array}$ \\
\hline Male & 20 & 28 & 13 & 61 \\
Female & 13 & 49 & 120 & 182 \\
\hline Total & 33 & 77 & 133 & 243 \\
\hline
\end{tabular}

Fischer's exact test: $p<0.001$.

\section{DISCUSSION}

There are reports in literature about other studies carried out in Brazilian populations using FRS for stratification of cardiovascular risk. The Bambui project had the purpose of quantifying the risk of IHD in a sample of individuals in the city of Bambui (MG) by using FRS for stratification of cardiovascular risk and concluding that the risk of IHD could be reduced to $44 \%$ in males and $38 \%$ in females ${ }^{(16)}$.

Evaluation of CVRF in a rural community in State of Bahia also used FRS for stratification of cardiovascular risk of the studied population and concluded that the CVRF, as well as SAH and hypercholesterolemia are frequently found in rural communities ${ }^{(17)}$.
Lipid and cardiovascular risk profiles in two populations in the Amazon, by using the National Education Cholesterol Program (NCEP III) and FRS, showed that the risks of the two populations were the same, but different prevention strategies should be applied $^{(18)}$.

The impact of cardiovascular risk in a sample of adult Portuguese individuals according to FRS revealed that the control of SBP in this population was the intervention with highest impact in the prevention of IHD and that better results can be achieved with simultaneous intervention of several factors ${ }^{(19)}$.

In this study, we observed a predominance of female individuals among the studied individuals. The higher number of females compared to males is possibly due to the fact of higher availability to attend public health units, given that, in most cases, male individuals represent a greater workforce for maintaining the domestic income, with a fear of being frequently absent from work and a risk of losing the job.

We also observed a higher frequency of elderly individuals in the studied sample, a fact that can be explained by the large number of retired individuals who attend the public health units in our country.

An increased percentage of individuals included in the study with FRS or associated conditions was characterized as individuals with high cardiovascular risk, with a predominance in the male gender.

Hypertriglyceridemia was not very frequent in the studied sample and it did not interfere in the calculation of LDL cholesterol in both genders. There was a predominance of normal triglyceride levels in the studied sample; however, when comparing the percentages of this parameter in each group it was observed that, among individuals with high cardiovascular risk there was a higher proportion of triglyceride levels $\geq 150 \mathrm{mg} / \mathrm{dL}$.

Among the individuals characterized directly as high cardiovascular risk, females presented a higher percentage of triglyceride levels above normal range compared with male individuals.

After elaboration of the risk stratification and establishment of the treatment goals of LDL-C levels previously described, most of the studied individuals showed controlled LDL-C levels; however, in the group with high cardiovascular risk, most individuals did not have controlled levels of LDL-C, i.e., $<100 \mathrm{mg} / \mathrm{dL}$.

This study disclosed a worrisome fact because a significant number of individuals (172, 45\%) characterized as high cardiovascular risk had clinical follow-up at a second-level public health unit, while they should be followed up at a third-level health unit, which denotes a distortion in the medical healthcare 
assistance flowchart foreseen in the Unified Health System for the city of Ribeirão Preto.

\section{CONCLUSION}

In view of the results presented, we observed a significant number of individuals characterized as a high and medium cardiovascular risk, according to FRS in the studied sample, especially in males, indicating the need of a closer follow-up of these patients.

\section{Acknowledgements}

Subsidiary source: National Council of Scientific and Technological Development (CNPq, Conselho Nacional de Desenvolvimento Científico e Tecnológico).

\section{REFERENCES}

1. Ramires JA, Chagas AC. Panorama das doenças cardiovasculares no Brasil. In: Nobre F, Serrano CV, editores. Tratado de cardiologia SOCESP. São Paulo: Manole; 2005. p. 7-46.

2. Sociedade Brasileira de Cardiologia-SBC; Sociedade Brasileira de HipertensãoSBH; Sociedade Brasileira de Nefrologia-SBN. V Diretrizes Brasileiras de Hipertensão Arterial. Arq Bras Cardiol. 2007;89(3):e24-e79.

3. Pan American Health Organization (PAHO). CARMEN: Initiative for integrated non-communicable diseases prevention in the Americas, 2004 [Internet]. [cited 2008 0ct 15]. Available from: http://www.paho.org/english/ad/dpc/ nc/carmen-info.htm

4. Mansur AP, Souza MF, Timerman A, Avakian SD, Aldrighi JM, Ramires JA. Tendência do risco de morte por doenças circulatórias, cerebrovasculares e isquêmicas do coração em treze Estados do Brasil, de 1980 a 1998. Arq Bras Cardiol. 2006;87(5):641-8.

5. Puffer PR, Griffit GW. Caracteristicas de la mortalidade urbana. Washington(DC): Organización Panamericana de la Salud; 1968. p. 191-205.

6. Ribeirão Preto. Prefeitura Municipal. Secretaria Municipal da Saúde. Departamento de Informática. Boletim do Sistema de Coleta e Análise de Estatística Vitais. Ribeirão Preto, SP; 1996. 4. p. 1-18.
7. Kannel WB. The Framingham study: Its 50-year legacy and future promise. Atheroscler Thromb. 2000;6(1):60-6.

8. Xavier HT. Risco cardiovascular na mulher. São Paulo: BBS; 2005. Estratificação do risco cardiovascular na mulher. p.47-54.

9. Lotufo PA. 0 escore de risco de Framingham para doenças cardiovasculares. Rev Med. 2008;87(4):232-7.

10. Saraiva FJ. Como estratificar o risco cardiovascular? In: Xavier HT. Manual de dislipidemias e cardiometabolismo. São Paulo: BBS; 2004. p. 55-66.

11. Silva ED, Martins JC. Rastreamento e tratamento de hipertensos de alto risco. Rev Soc Bras Clin Me. 2005;3(2):46-8.

12. Chobanian AV, Bakris GL, Black HR, Cushman WC, Green LA, Izzo JL Jr Jones DW, Materson BJ, Oparil S, Wright JT Jr, Roccella EJ; National Heart, Lung, and Blood Institute Joint National Committee on Prevention, Detection, Evaluation, and Treatment of High Blood Pressure; National High Blood Pressure Education Program Coordinating Committee. The Seventh Report of the Joint National Committee on Prevention, Detection, Evaluation, and Treatment of High Blood Pressure: the JNC 7 report. JAMA 2003;289(19):2560-72. Erratum in: JAMA. 2003 Jul 9;290(2):197.

13. Expert Panel on Detection, Evaluation, and Treatment of High Blood Cholesterol in Adults. Executive Summary of The Third Report of The National Cholesterol Education Program (NCEP) Expert Panel on Detection, Evaluation, And Treatment of High Blood Cholesterol In Adults (Adult Treatment Panel III). JAMA. 2001;285(19):2486-97.

14. Santos RD; Sociedade Brasileira de Cardiologia. III Diretrizes Brasileiras sobre Dislipidemias e Diretriz de Prevenção da Aterosclerose do Departamento de Aterosclerose da Sociedade Brasileira de Cardiologia. Arq Bras Cardiol. 2001;77(Supl 3):1-48.

15. Friedwald WT, Levy RI, Fredricsons DS. Estimation of the concentration of low-density lipoprotein cholesterol in plasma, without use of the preparative ultracentrifuge. Clin Chen. 1972;18(6):499-502.

16. Barreto SM, Passos VM, Cardoso AR, Lima-Costa MF. Quantifying the risk of coronary artery disease in a community: the Bambui project. Arq Bras Cardiol. 2003;81(6):556-61.

17. Matos AC, Ladeia AM, Assessment of cardiovascular risk factors in a rura community in the Brazilian state of Bahia. Arq Bras.Cardiol. 2003;81(3): 291-302.

18. Feio CM, Fonseca FA, Rego SS, Feio MN, Elias MC, Costa EA, et al. Lipid profile and cardiovascular risk in two Amazonian populations. Arq Bras Cardiol. 2003;81(6):596-9.

19. Friões F, Azevedo A, Castro A, Alvelos M, Pimenta J, Vazquez B, et al. Impact of cardiovascular risk factors in an urban sample of Portuguese adults according to the Framingham risk prediction models. Rev Port Cardiol. 2003;22(4):511-20. 